\title{
LOS MAREANTES PONTEVEDRESES Y LA PESCA DE ALTURA EN EL SIGLO XVI
}

\author{
XOSÉ MANUEL PEREIRA FERNÁNDEZ \\ Universidad de Santiago de Compostela
}

\begin{abstract}
Resumen
Durante buena parte del siglo XVI la villa de Pontevedra aparece como el mayor y más dinámico núcleo urbano del Reino de Galicia, con una economía asentada en la pesca y el comercio marítimo. Frente a la visión tradicional, que considera a los hombres del mar de las Rías Baixas gallegas como pescadores de bajura, la documentación notarial pontevedresa del siglo XVI informa de su presencia tanto en Terranova como en el banco de pesca canario. De esta forma se muestran fieles continuadores de una vocación de relación con el exterior por vía marítima presente desde la Baja Edad Media.
\end{abstract}

\section{Palabras Clave}

Pontevedra, Terranova, Rías Baixas gallegas, pesca, banco de pesca canario, bacalao.

\begin{abstract}
During most of the 16th century, the town of Pontevedra was recorder as the most dynamic urban centre of the Galician kingdom for its economy based on fishing and sea trade. In contrast with the traditional view which has always regarded the seamen from Rias Baixas as coastal fishermen, Pontevedra's historical legal documents from the Sisteenth Century provide evidence of their presence in Newfoundland and the Canary Island fishing grounds. In the light of this evidence, those seamen appear as faithful continuers of a tradition of seafaring relationships with foreign countries dating back to the late Middle Ages.
\end{abstract}

\section{Key Words}

Pontevedra, Newfoundland, Rias Baixas, fishing, Canary Island fishing grounds, cod. 
$\mathrm{P}$ arece no existir duda de que uno de los términos más en boga últimamente es el de globalización, proceso que levanta tanto apasionadas defensas como furibundos ataques. Por contra, aparenta ser bastante escasa la atención a los pioneros de la mundialización, sobre todo cuando se analiza la producción española al respecto. Tradicionalmente, la historiografía hispana siempre relegó a un segundo plano los estudios marítimos ${ }^{1}$, aunque fue en el mar donde el espacio territorial que actualmente recibe el nombre de España alcazó algunas de sus mayores cotas de brillantez, sino las que más. Paralelamente, su homónima gallega, salvo honrosas excepciones, tuvo y tiene en el estudio del mar la gran asignatura pendiente, a pesar de su decisiva importancia en todas las estructuras -económicas, sociales, humanas...- de Galicia, sobre todo en la doble vertiente comercial y pesquera. En un orden de cosas similar, los medios de comunicación tampoco parecen haber prestado una especial atención al tema y, en la práctica, han ignorado el proceso de ruptura -de vivir de espaldas al mar- al que está asistiendo la sociedad española en los últimos tiempos. Mientras, el resto de los países con intereses marítimos parecen encontrarse inmersos en un esfuerzo tendente a ampliar, lo más posible, sus áreas de competencias jurisdiccionales marítimas.

Posiblemente sea conveniente recordar que fueron los hombres del mar del litoral cántabro-atlántico de la Península Ibérica -junto con alguna aportación mediterránea- los grandes protagonistas de la expansión oceánica, quienes en un espacio de tiempo relativamente corto, con sus conocimientos, con sus barcos, con sus experiencias, con su tecnología..., fijaron las grandes rutas mundiales de navegación. Paralelamente, determinaban en el subconsciente colectivo una nueva imagen de mundialización planetaria, el precedente de lo que hoy en día conocemos como globalización.

Proceso de conocimiento oceánico y fijación de rutas que recibe el primer gran impulso y aceleración con la creación, en torno a 1420, de la Escuela de Navegación de Sagres por el infante portugués Enrique el Navegante, y que se puede dar por concluido en 1565, cuando el guipuzcoano Andrés de Urdaneta sea capaz de

\footnotetext{
${ }^{1}$ A modo de ejemplo, una serie de autores han considerado a la pesca y la gente del mar andaluces como la cenicienta de los estudios de su sector primario, afirmando que constituye uno de los grandes vacíos de la historiografía andaluza. Vid.: Burgos Madroñero, Manuel, «La Matrícula de Mar en Andalucía. Siglos XVIII y XIX», en Actas del II Congreso de Historia de Andalucía. Córdoba, 1991. Andalucia Moderna. Tomo I, Córdoba, 1995, p. 349; Cuenca Toribio, José Manuel, Andalucía. Una introducción histórica, Córdoba, 1980, pp. 187-188; Villas Tinoco, Siro, «La fundación del gremio de patrones, armadores y marineros de Málaga», Baetica. Estudios de arte, geografia e historia, $\mathrm{n}^{\circ} .7$, Málaga, 1984, p. 321.
} 
regresar de Asia a la costa oeste del continente americano y fija la que posteriormente recibirá el nombre de Ruta de Poniente. En este contexto de expansión del conocimiento geográfico oceánico, mientras que los hombres y barcos del Reino de Portugal fueron los primeros en llegar a las Molucas - la tierra de las especiasnavegando siempre hacia el este, a la Corona de Castilla le correspondió el mismo puesto derrotando hacia el oeste. De forma paralela, los años de 1519-22 contemplaron como una empresa de la Corona de Castilla, financiada por la Corona de Castilla, dirigida en un primer momento por el portugués Fernando de Magallanes y concluida por el guipuzcoano Juan Sebastián Elcano, circundaba por primera vez el planeta y demostraba su esfericidad.

Dentro de este proceso de expansión oceánica que estamos analizando, todo parece indicar que el área de mayor potencial pesquero del litoral cántabro-atlántico de la Península Ibérica se localizaba en las Rias Baixas gallegas. Dentro de ellas, el mayor puerto pesquero aparecía situado en la desembocadura del río Lérez, al tiempo que la, en aquel entonces - por Pegerto Saavedra denominada- «efervescente ${ }^{2}$ villa de Pontevedra se muestra durante gran parte del siglo XVI como el mayor y más dinámico núcleo urbano de Galicia, con una economía asentada en dos grandes pilares: la pesca y el comercio marítimo de doble dirección norte-sur.

En su momento, Pegerto Saavedra señaló que posiblemente en níngún otro momento del Antiguo Régimen tanta gente se dedicó a la pesca en Galicia como sucedió en el siglo $\mathrm{XVI}^{3}$. A modo de ejemplo, si en un recuento nominal de vecinos residentes en Pontevedra -pecheros y no pecheros- realizado en 1588 con una finalidad fiscal ${ }^{4}$ declaran la profesión ejercida casi el 70 por ciento de los cabezas de familia, informando prácticamente el 45 por ciento de los mismos ser mareantes o pescadores ${ }^{5}$, en la villa de Pontedeume de 1571 , de cada tres hombres, dos afirman tener como profesión la pesca ${ }^{6}$.

La importancia de la pesca y el comercio por vía marítima también aparece señalada al estudiar la fiscalidad pontevedresa. Las cantidades que Pontevedra paga a la Hacienda Real en concepto de alcabalas durante el reinado de Felipe II, expresan que el monto alcabalatorio correspondiente al pescado descendió del 40

${ }^{2}$ Saavedra Fernández, Pegerto, La Galicia del Antiguo Régimen. Economía y Sociedad, A Coruña, 1991, p. 122.

${ }^{3}$ Saavedra Fernández, P., Opus. Cit., p. 129.

${ }^{4}$ Archivo General de Simancas (A.G.S.), Sección Expedientes de Hacienda, Leg. 144-38.

${ }^{5}$ Sobre las dedicaciones profesionales del recuento pontevedrés de 1588 ver: Pereira Fernández, Xosé Manuel, A Pontevedra de Felipe II, Valga 2000, pp. 92-96.

${ }^{6}$ Saavedra Fernández, P., Opus. Cit., p. 129. 
por ciento del total únicamente en 1579 y 1587 , y superan el 50 por ciento en varias ocasiones. Al mismo tiempo, la suma del importe de la cantidad cotizada por las ventas del pescado y el vino -Pontevedra era el puerto natural de salida del vino de la comarca del Avia- siempre superó el 60 por ciento del total, y se situó durante varios años por encima del 70 por ciento 7 .

La vocación marinera y de relación con el exterior por vía marítima de Pontevedra muestra una tradición secular, pues ya en 1296 la pontevedresa Santa María conseguía un salvoconducto del monarca inglés para realizar operaciones comerciales entre Inglaterra y Galicia a pesar del contexto bélico existente que enfrentaba a Castilla y Francia con Inglaterra ${ }^{8}$. En un orden de cosas similar, el estudio realizado por Ferreira Priegue señala la permanente presencia de barcos y hombres del mar pontevedreses en el Mediterráneo durante la Baja Edad Media9 . Si invertimos los términos, el tráfico marítimo fue la decisiva actividad causante de que uno de los rasgos más característicos de la Pontevedra del siglo XVI lo constituyese su marcado cosmopolitismo, informando la documentación del permanente caminar por sus calles de franceses/bretones, flamencos, portugueses ${ }^{10} \mathrm{y}$ vecinos del litoral cántabro o de otros puntos de la Península Ibérica, junto con la exótica -aunque siempre lamentable- presencia de esclavos, posiblemente con una función de prestigio y realce social y no tanto de producción ${ }^{11}$.

\footnotetext{
${ }^{7}$ Para una visión de la fiscalidad pontevedresa del siglo XVI y primer tramo del XVII ver: Pereira Fernández, X.M., Opus. Cit., pp. 221-269, Pereira Fernández, Xosé Manuel, «Pontevedra en el siglo XVI. Contribución al estudio de la historia urbana de Galicia», Obradoiro de Historia Moderna, núm. 6, Santiago de Compostela, 1996, pp. 253-261.

${ }^{8}$ Armas Castro, José, Pontevedra en los siglos XII al XV. Configuración y desarrollo de una villa marinera en la Galicia medieval, Pontevedra, 1992, pp. 199-200; Ferreira Priegue, Elisa, Galicia en el comercio marítimo medieval, La Coruña, 1988, p. 611; Pallares Méndez, María del Carmen / Portela Silva, Ermelindo, Galicia na época medieval, A Coruña, 1991, p. 208.

${ }^{9}$ Ferreira Priegue, E., Opus. Cit.; Ferreira Priegue, Elisa María, Fuentes para la exportación gallega de la segunda mitad del siglo XV: El peatge de mar de Valencia, Santiago de Compostela, 1984.

${ }^{10}$ Naturales del vecino Reino que fieles a su gran tradición marinera, durante gran parte del siglo XVI parecen monopolizar la actividad de «maestros de navío» de gran parte de los barcos que atracan en el puerto pontevedrés. Paralelamente, con una cronología similar, según Amandio Jorge Morais Barros, a quien agradecemos la información, en las operaciones de entrada y salida del puerto de la ciudad de Oporto destacó el papel mostrado por los gallegos como «maestros de barra».

${ }^{11}$ Para una mayor información del cosmopolitismo pontevedrés durante el siglo XVI ver: Pereira Fernández, X.M., Opus. Cit., pp. 35-37; Pereira Fernández, Xosé Manuel, «Las interrelaciones del mayor núcleo urbano gallego del siglo XVI: Pontevedra», Actas del Congreso Las sociedades ibéricas y el mar a finales del siglo XVI. Tomo IV. La corona de Castilla, Madrid, 1998, p. 361; Pereira Fernández, José Manuel, «Pontevedra y el mar en tiempos de Carlos I», AA.VV., Hombres y Armadas en el reinado de Carlos I, Madrid, 2000, pp. 29-30; Pereira Fernández, Xosé Manuel, «La villa de Pontevedra en el siglo XVI. Un esbozo», Nodales 2001, Pontevedra, 2001, pp. 40-41.
} 
La visión tradicional existente en algún momento, que presentaba a los hombres del mar de las Rías Baixas gallegas como pescadores de bajura, por oposición a los del litoral cántabro, siempre más avezados a adentrarse en aguas más procelosas, es rechazada actualmente mismo por autores de la citada fachada ${ }^{12}$. La documentación notarial pontevedresa presenta a sus moradores como verdaderos lobos de mar capaces de, previo artillado de sus barcos ${ }^{13}$, dirigirse al Atlántico Norte a la pesca del bacalao, como sucede en $1578^{14}$ y $1579^{15}$. El desplazamiento a Terranova se realizaba en el mes de marzo ${ }^{16}$, fuera de la temporada de los cercos, campaña que presentaba una duración aproximada del 21 de septiembre a Navidad y durante la cual se conseguía el mayor volumen de extracción piscícola y se obtenía la mayor rentabilidad económica ${ }^{17}$. En su momento, Ferreira Priegue ya informó de la posible presencia de pontevedreses en Terranova en

${ }^{12}$ «Lo que de modo alguno [se está refiriendo a la pesca de bajura en las rías y litoral gallegos] debe llevar al error de creer que los mareantes gallegos dejaran de practicar la navegación de altura en los mismos horizontes que sus demás vecinos del Cantábrico», Casado Soto, José Luis, «Carlos V y la construcción naval en España», Catálogo exposición Carlos V. La náutica y la navegación, Barcelona, 2000, pp. 130 y 142, nota 30

${ }^{13}$ Presumiblemente de forma similar a como lo realizaban los vecinos portugueses, según informa Magalhães Godinho: «A $<<$ Ley de como ham de ir armados os navios $\gg>$ de 1571 (...) determina em relação às $<<$ naos que forem das vilas de Aveiro, Viana e de qualquer outra parte de meus reinos e senhorios à pescaria do bacalhao $>>$ que vão armadas...», Magalhães Godinho, Vitorino, Os descobrimenos e a economia mundial. Vol. IV, Lisboa, 1991 (1', 1963-1971), p. 135.

${ }^{14}$ Archivo Histórico Provincial de Pontevedra (A.H.P.Po.), Sección Protocolos Notariales, Leg. 904 (2) fs. $27 \mathrm{r}^{\mathrm{0}} .-29 \mathrm{r}^{\circ}$.

Según Magalhães Godinho: «por alturas de 1578, calcula-se que frequentem a pescaria do bacalhau da Terra Nova umas 50 velas inglesas, uma centena de espanholas, além de 20 ou 30 biscainhas, umas 150 francesas e uma cinquentena de portuguesas», Magalhães Godinho, V., Opus. Cit., Vol. IV, p. 135.

${ }^{15}$ A.H.P.Po., Sec. Prot. Not., Leg. 904 (3), fs. $11 \mathrm{r}^{\circ} .-14 \mathrm{r}^{\circ}$.

${ }^{16}$ Para la pesca del bacalao, los vascos se dirigían a Terranova en los meses de marzo y abril, regresando en septiembre-octubre. Vid.: Fernández Duro, C., Opus. Cit., p. 297 (existe edición facsímil, Madrid 1995); García de Cortázar, José Ángel / Arizaga Bolumburu, Beatriz / Ríos Rodríguez, María Luz / Val Valdivieso, Isabel del, Vizcaya en la Edad Media. Evolución demográfica, económica, social y política de la comunidad vizcaina medieval (II), San Sebastián, 1985, p. 102, nota 375; Labayru y Goicoechea, Estanislao Jaime de, Historia General del Señorío de Bizcaya. Tomo I, edición facsímil, Bilbao, 1968 (1ª., Bilbao/Madrid, 1895), p. 602.

${ }^{17}$ Sobre la temporada y pesca de los cercos pontevedreses en el siglo XVI y primer tramo del XVII ver: Pereira Fernández, X.M., Opus. Cit., pp. 132-168; Pereira Fernández, X.M., «Pontevedra en el siglo XVI...», pp. 246-253; Pereira Fernández, X.M., «Pontevedra y el mar...», pp. 43-51; Pereira Fernández, Xosé Manuel, «La pesca en el S. XVI. El esplendor de Pontevedra», AA.VV., Historia de las rías. Vol. II, Vigo, 2000, pp. 731-740. 
$1518^{18}$. En los tres casos documentados la embarcación utilizada fue una nao, de mayor porte en 1578 y menor al año siguiente ${ }^{19}$, de seguir a Labayru y Goicoechea ${ }^{20}$. El hecho de que las fechas de los documentos localizados abarquen un amplio espacio temporal, la circunstancia de que en los contratos de 1578 y 1579 los participantes se concierten de nuevo para el año siguiente, aspecto que parece revelar una pauta de actuación fijada por la experiencia, unido a la existencia de una inmensa masa documental de base notarial que no ha sido explorada hasta el presente y no resulta improbable que pueda contener más evidencias, son elementos que permiten proponer la hipótesis de la continua presencia de pontevedreses en Terranova pescando bacalao durante buena parte del siglo XVI.

\footnotetext{
18 «...el bacalao que desde fines del XV estaba retirándose de la costa atlántica, tal vez por el mismo cambio ecológico que alejó a las ballenas algo más tarde: el calentamiento de las aguas, favorable a su vez a la sardina, que por estas fechas empieza a proliferar en Bretaña. Su exportación por los gallegos no aparece documentada en los puertos mediterráneos en los registros que he consultado, hasta 1500. Cuando la pesca del bacalao adquiere carácter de pesca de altura, y los gallegos salen de sus bases habituales en su búsqueda, tal vez a Terranova, se abre una nueva etapa, precisamente uno de los hitos que delimitan este estudio.

Normandos y portugueses fueron, según todos los indicios, los pioneros de las expediciones a Terranova. 1506 es la fecha de la primera expedición portuguesa y en 1508 ha localizado Mollat la primera normanda. (...)

En 1517 los bacalaos ya habían desaparecido totalmente de la costa atlántica y no se pescaban más que en Terranova. De ese año data la primera expedición salida de Bordeaux, y de un año después un contrato datado en Pontevedra a 10/5/1518 en el que el marinero Juan de Betanzos se $<<$ aluga $>>$ con el mercader de Pontevedra Fernando de la Torre, $<<$ del dia de la fecha desta carta fasta quel navio e naao de vos el dicho Fernando de la torre venga de los bacallaaos e sea amarrado a la barca de la Merced de la dicha villa, en la qual eu por voso mandado teño de yr en el dicho navío a pescar para vos los dichos peyxes... >>. Es una operación de pesca de altura, a la que se va con una nao y por un período de tiempo prolongado; todo parece indicar que se trata de la más antigua expedición de los gallegos a Terranova que tenemos documentada hasta el momento», Ferreira Priegue, E., Galicia en el comercio..., p. 148. Ver también: Ferreira Priegue, Elisa, «O desenvolvemento da actividade pesqueira desde a Alta Idade Media ó século XVII», en Fernández Casanova, Carmen (Coord.), Historia da pesca en Galicia, Santiago de Compostela, 1998, p. 80.

Referido a Guipúzcoa, García de Cortázar escribe que «los documentos, por su parte, prueban que las navegaciones de los guipuzcoanos a Terranova y a la pesca del bacalao no son muy anteriores al año 1540», García de Cortázar y Ruiz de Aguirre, José Ángel, Vizcaya en el siglo XV, Bilbao, 1966, p. 116.

${ }^{19}$ De igual tipología eran, según Fernández Duro, las naves guipuzcoanas empleadas para desplazarse a Terranova a la pesca del bacalao. Vid.: Fernández Duro, C., Opus. Cit., p. 297.

${ }^{20}$ Este autor indica que «la tripulación de cada buque destinado al bacalao consistía en 25 hombres si la cabida de la nave era de 150 toneladas; 20 si medía 100 , y 12 á 16 hombres si contaba 25 toneladas», Labayru y Goicoechea, E.J. de, Opus. Cit., p. 602. Ver también: García de Cortazar, J.A. / Arizaga Bolumburu, B. / Ríos Rodríguez, M.L. / Val Valdivieso, I. del, Opus. Cit., p. 102, nota 375.
} 
En este contexto, no tenemos la impresión de que el desplazamiento a las islas Canarias presentase dificultades insalvables a los hombres del mar de la Pontevedra del Quinientos. Si a este hecho se añade la circunstancia de que desde las primeras décadas del siglo XV está documentada la presencia en los prolíficos bancos de pesca de Marruecos, África Occidental y Canarias $^{21}$ de pescadores de la cornisa cantábrica, acompañando a andaluces y portuguese ${ }^{22}$, no parece sorprendente que el 26 de septiembre de 1523, Rodrigo de Cordeiro, Juan de Camanço, Juan Gonsales, Esteban Rodrigues o Moço, Juan Davilles o Moço y Pedro Tilleiro o Moço, mareantes vecinos del arrabal pontevedrés de la Moureira, se reuniesen ante el notario de Pontevedra García do Sixto para suscribir un documento mediante el cual se concertaban para ir a pescar al Banco Canario a partir del primero de enero de $1524^{23}$, igualmente fuera de la temporada de los cercos. Desplazamientos a Terranova y banco de pesca canario fuera de la temporada de los cercos y que parecen indicar una pauta de actuación que tendría como norte la búsqueda de una optimización de rendimentos y beneficios.

${ }^{21}$ Sobre la importancia de estos caladeros ver: Magalhães Godinho, V., Opus. Cit., Vol. IV, pp. 129-134; Romeu de Armas, Antonio, «Las pesquerías españolas en la costa de África (Siglos XVXVI)», Hispania, nl 130, Madrid, 1975, pp. 295-319.

${ }^{22}$ Casado Soto, José Luis, «El arte de navegar en el Atlántico en la época del Tratado de Tordesillas», en Actas de El Tratado de Tordesillas y su época. Congreso Internacional de Historia. Tomo II, Madrid, 1995, p. 988; Casado Soto, José Luis, «Los barcos de la expansión oceánica española», en XVIII Semana de estudios del mar, Pontevedra, 2000, pp. 204-205; Romeu de Armas, A., art. cit., pp. 295-319.

${ }^{23}$ A.H.P.Po., Sección Ayuntamiento, Legajo 128 (10), fs. $71 \mathrm{r}^{\mathrm{o}} .-72 \mathrm{r}^{\mathrm{o}}$. 


\title{
ARCHIVO HISTÓRICO PROVINCIAL DE PONTEVEDRA (A.H.P.Po.)
}

\author{
Sección Protocolos Notariales Legajo 904 (2)
}

$\left(X X V I I r^{\circ}\right)$ En el nonbre de Dios Amen sepan quantos esta escritura / y contrato vieren como nos las perssonas y partes yusso conte / nidas hes a ssaver de la una parte gonçalo de ssan bizente y fernando / de ssanbizente vezinos de la villa de pontebedra maestros / y señorios despues de Dios de su nao nonbrada nuestra señora / de la humildad surta y amarrada en el rrio desta / villa que dios salve y guarde y gonçalo maçiço y Juan / Domato y pedro de pintos y mateo rrodriguez y gon / çalo dominguez vezinos de la dicha villa y marineros / de la dicha nao susso nonbrada por nos y en nonbre de los / mas marineros abaxo contendidos por los quales y cada / uno dellos hazemos y prestamos cauçion de rato judi / catud solvendo que habran por bueno lo aqui dicho y espa / çificado en esta scriturass o obligaçion que por hello / hazemos de nuestras personas y bienes y de la otra parte / juan ssanchez diaz pedro dotero notario del numero de la dicha / villa y juan trigo mercader vezinos ansy mysmos de la / dicha villa de ponte bedra otorgamos y conoze / mos poresta presente carta y dezimos que por quanto / entre nos hesta tratado y conçertado de hazer como por la presente hazemos el contrato en la forma / y manera siguyente que nos los dichos gonzalo e fernando / de ssanbizente nos obligamos de dar y que daremos la dicha / nuestra nao nonbrada nuestra señora de la humyldad / segura y estanca de quylla costado galafeteada bien / adreçada hartillada belejada y canalada de todas las / belas analas para a y aparejos y marineros y gente / nesçessaria que basten para le rregir y gobernar / que an de ser beinte y quatro marineros glometes / y pajes sufiçientes para hazer y seguir biaje a la / tierranueba por nuestras perssonas en la dicha nao (XXVII $v^{\circ}$ ) a la pesca Del bacallao que en la dicha tierra nueba / se suele y ha de hazer mediante dios nuestro señor y pon / dremos piloto de costa para seguir el dicho biaje a nuestra costa / y mysion con que bos el dicho Juan ssanchez y conssortes abeys / de dar diez ducados para ayuda de todo lo quel dicho piloto / por razon dello nos ubiere de llebar y forneçer la dicha / nuestra nao de los bastimyentos y cossas que fuere menester y tu / biere nesçesidad para hazer la dicha biaje a la dicha Tierra nueba / y estada en ella y buelta asta que se sea llegada a esta dicha / villa mediante la boluntad de dios e nos los dichos juan sanchez / pedro dotero y juan trigo dezimos y nos obligamos de bastezer / y forneçer la dicha nao a bos los dichos maestros y marineros / de las cossas siguientes primeramente bos daremos y / entregaremos para el forniçamyento de la dicha nao qynyentos / çelemynes de trigo en grano para que bos los dichos maestros / y marineros los hagais moler y coçer y pagaremos / lo que costare el horno y coçedura del dicho pan e / mas doze pipas de bino roçete las quales bos / daremos la una dellas de tinto de la tierra / desta dicha villa de pontebedra y las demas en la villa / de abeiro que sea buen bino y merchante como se suele / y acostunbra llebar por otras naos en semejante / biaje y si en esta dicha villa bos dieremos bino / seran ocho pipas de bino ullao de la tierra / bueno y tres pipas de bino blanco de rribadabia / con sus cascos y mas tres bacas çevadas y ocho arro / bas de açeite y quatro arrobas de binagre una / hanega de castaña seca pilada y bos daremos ansi / mysmo quatro barcos para pescar que se an de hazer / en la dicha villa de abeiro sufyçientes conforme / a la calidad de la dicha nao y una dornylla pequena / en esta dicha villa de mas de los dichos barcos y sesenta / cordeles de pescar y dosçientos amuzelos y quatro / betas bagueiras y la ferramenta nesçessaria / que conbenyente sea para la dicha pesca y diez (XXXVIII $r^{\circ}$ ) myllares de ssal benca y sufiçiente para la dicha pesca y si mas / o menos fuere nesçessaria y conbeniente se la daremos o qyta / remos y ansy mysmo bos daremos las belas y amarras nesçessa / rias para los dichos quatro barcos la qual dicha ssal y barcos / y los demas aparejos aqui dichos conforme de susso se contiene / bos daremos puestos dentro de la barra de abeiro en donde / bos los dichos maestros e mari- 
neros con la demas gente abyes / de yr con la dicha nao a lo tomar y resçivir a donde nos los / Dichos juan ssanchez y pedro dotero y juan trigo os lo da / remos todo ello enteramente a nuestra costa y mysion / con que algunos delos dichos maestros y marineros lo bayan / aber medir y resçivir y os daremos esteras / que fueren menester para debaxo de la dicha ssal y la parte / que nos cupiere del terçio de las abarias y liman y piti / liman y abarias acostunbradas lo qual todo / que dicho hes nos los dichos maestros y marineros con la dicha nuestra / nao tomaremos y resçiviremos luego que la dicha nao / hestubiere adreçada y aparejada para ello y lo / haremos con toda la deligençia que ser pueda / y tienpo haziendo y no perdiendo seguiremos derecho / biaje a lo tomar y resçivir y cargar a la dicha billa / y rria de abeiro e por rrazon de todo lo contenydo dicho / y espaçyficado en esta scritura que ansi nos days / para forniçimyento de la dicha nuestra nao y bastimyentos / que en ella hemos de cargar y llebar a la dicha tierra / nueba para hazer la dicha pesca nos los susso dichos / maestros y marineros por nos y en el dicho nonbre / ssola dicha cauçion nos obligamos de dar y entregar / Daremos y entregaremos luego que llegaremos en / ssalbamyento a esta dicha villa siendo dios serbido / con la dicha nuestra nao y pesca que dios nos diere al[roto] / los dichos Juan ssanchez y pedro dotero y Juan Trigo / la terçia parte enteramente de toda la pesca / de bacallao y de otro genero que sea qualquier / pescado que ansi tomaremos o truxieremos en la dicha nao / y de toda la graçia que dello ssaliere y se hiziere conque (XXXVIII $\mathrm{V}^{\circ}$ ) primero y ante todas cossas demas de la dicha terçia parte que ansi bos / hemos de dar de todo lo que dicho hes bos daremos quatro / myllares de bacallao de bantaje y ansy mysmo bos daremos / y entregaremos la terçia parte de todas las baras maderas / y otras cossas que dende la dicha tierra nueba a esta dicha / villa traxeremos y hes condiçion entre nos las / dichas partes que despues de ansi llegada la dicha nao / a esta dicha villa y ssacado la pesca que en ella binyere / bos daremos y entregaremos nos los dichos maestros / a bos los dichos mercaderes y fornidores la ssobra / de todo el pan y bino barcos y linas y amozelos / betas y todo lo mas fornymyento que ansi sobrare / de lo que ansi nos days para yr a la dicha tierra nueba / y pesca susso dicha otrosi hes condiçion que abiendo / de yr la dicha nao otra semejante biaje a la dicha tierra / nueba para el año benydero de myll y quynyentos e setenta / y nuebe años que queriendola fornir y bastezer / bos los dichos juan ssanchez y conssortes no bos la podamos / quytar por darla a otros y que primero seais pre / feridos que otros ningunos y para ello bos lo hare / mos ssaver e nos los dichos Juan ssanchez pedro dotero y juan / trigo dezimos que ansi açeptamos e consentimos todo / lo contenido en esta scritura y queda en condiçion entre / nos los dichos mercaderes y fornidores que porque bos / el dicho Juan trigo por bos mysmo e ynssolidund poneis a vuestra / costa y mysion la mytad enteramente de todo el ynteres / bastimyento y fornymyento que ansi damos a los dichos / maestros y marineros que lleban en la dicha nao para la dicha / tierra nueba que ansi abeis de llebar por razon dello / para bos mysmo la mytad enteramente de todo lo que / ansi nos dieren de la dicha pesca de bacallao y todo / lo mas que dicho hes los dichos maestros y marineros / y dellos obieremos de aver conforme a lo aqy puesto / dicho y declarado y luego que nos fuere entregado bos / acudiremos con la dicha mytad e todas las dichas partes / e cada uno de nos por lo que nos toca y aqui se obliga (XXIX ro ) De guardar y cunplir en esta scritura ansi lo guardaremos y cunplire / mos llanamente sso pena de los yntereses daños y menoscabos / que se sigueren y recreçieren conforme a la ganançia que truxieren / naos y navios de semejante porte que ban de abeiro a la dicha tierra nueva / y costas y gastos que sobre ello se hizieren que den y paguen las personas / que no lo cunplieren a las que lo cunplie-ren y para la seguridad / ssaneamyento dello ypotecamos los unos a los otros y los otros / a los otros la dicha nao y aparejos y belas della y mercadoria for / nimyento de bastimyento y para ello obligamos nuestras personas / y bienes muebles y raizes avidos y por aver y damos poder qunpli / do a las justiçias de su magestad a cuya jurdiçion nos ssometemos e rre / nunçiamos nuestro propio fuero juridiçion y domyçilio y la ley sid con / beterid de juridiçiones o ninun judiçiones para que nos apremyen e / cunplir bien ansi y 
a tan conplidamente como si fuesse [roto] / de juez conpetente por nos consentida y passada en cosa otor / gada ssobre lo qual todo renunçiamos a todas y quales / leyes fueros y derechos en nuestro favor y a la ley e derecho / que dize que general rrenunçiaçion de leyes fecha que / balga en testimonio e firmeça de lo qual otorgamos / esta carta en la manera que dicho hes ante escrivano y notario / publico de su magestad y del numero de pontebedra y testigos / que fecha y otorgada en la villa de pontebedra / a catorze dias del mes de hebrero de myll y quinientos / y setenta y ocho años testigos que fueron presentes / a lo que dicho hes toribio martinez Leal y Francisco [)?] / e pedro de ssantisso pichelero vezinos y estantes / en la dicha villa y firmaronlo de sus nonbres / los que dixeron que ssabian scrivir y por / que dixeron no ssabian hescrivir lo firmo un / testigo a su ruego a los quales otorgan-tes yo / presente escrivano doy fee que conozco.

\title{
ARCHIVO HISTÓRICO PROVINCIAL DE PONTEVEDRA (A.H.P.Po.)
}

\author{
Sección Protocolos Notariales Legajo 904 (3)
}

$\left(\mathrm{XIr}^{\circ}\right) \mathrm{SePan}$ quantos esta escritura y contrato bieren como / nos las partes y personas yusso conteydas / hes ssaver de la una parte juan nyeto y bastian de amarante / el moço vezinos de la villa de ponte vedra maestros e señores de la nao nonbrada santa cruz surta y amarrada / en el rrio de la dicha villa y diego de hontiveros / tavoada y francisco rruiz de liebana rreçetores de los / alfolis de ssal de la dicha villa de pontebedra dela / otra parte e dezimos que por quanto entre nos / hesta tratado y conçertado de hazer como por la presente / hazemos el contrato en la forma y manera siguyente / que nos los dichos Juan nyeto e bastian damarante por / nos mysmos y en nonbre de los marineros y personas / que han de ser en nuestra conpañya y hazer biaje / de lo que a yusso sera contenido por quyen hazemos / cauçion de rrato y grato judicatud solbendo / questaran y pasaran por lo contenido en esta / escritura nos obligamos de dar y que da / remos la dicha nuestra nao suso nonbrada segura / hestanca de quyla costado galafeteada / hartillada belazada y avalada y bien / adreçada de todas las belas con las jara y / aparejos y marineros y gente nesçesaria que / basten para le rregir y gobernar que an de / ser catorze partidas de soldadas sufiçientes $\left(\mathrm{XIv}^{\circ}\right)$ e quatro barcos para hazer pesqueria / para hazer y seguir biaje a Tierra nueba por nuestras / personas en la dicha nao a la pesca del bacalao que / en la dicha tierra nueba se suele y ha de hazer / mediante dios nuestro señor y hemos de poner piloto / de costa para seguir el dicho biaje a nuestra costa $\mathrm{e} /$ mysion conque bos el dicho diego de hontiberos / e francisco rruiz de liebana nos abeys de dar diez / ducados para ayuda de todo lo quel dicho / piloto por rrazon dello nos obiere de llebar / y fornocer la dicha nuestra nao de los bastimyentos y / cossas que fueren menester y tubiere nesçesidad / para hazer la dicha biaje a la dicha tierranueba / y estada en ella y buelta asta que sea llegada / a esta dicha villa mediante la boluntad de dios / e nos los dichos diego de hontiveros y francisco rruiz / de liebana dezimos y nos obligamos de bastezer / e fornezer la dicha nao a bos los dichos Juan nyeto / e bastian de amarante de todo lo nesçesario / ques menester que por todo ello conbiene / que por rrazon de lo que ansi pedis y de / mandays de todo bastimyento y fornyçimiento / de la dicha nao e biaje della a la dicha Tierra nueba / ssomos y estamos conçertados en que bos / demos y paguemos tresçientos y çinquenta / ducados de a honze reales cada uno y ansi / luego os damos y pagamos de contado en presen / çia del presente notario publico e testigos desta / carta los dichos tesçientos y çinquenta $\left(\mathrm{XIIr}^{\circ}\right)$ ducados en rreales de plata y scudos de oro / y otra moneda castellana que los sumaron / e montaron los quales dichos Juan nyeto / e bastian damarante los rresçivimos en nuestro / poder de la qual paga entrego e resçibo delos / dichos tresçientos y çinquenta ducados yo el / dicho escrivano y notario publico doy ffee que se hizo / en my presençia y de los dichos testigos en la 
dicha moneda / y nos contentamos nos los dichos maestros e / señorios con los dichos tresçientos y çinquenta / ducados que ansi rresçivimos por todo el dicho / bastimyento e fornymyento de lo ques nesçesario / para la dicha nao y biaje della y se suele y a / costunbra dar por otros mercaderes para / fornyçimyento de semejantes naos que ban a la / dicha tierra nueba e pesca de bacallao y ansi / mysmo nos los dichos diego de hontiberos y francisco / Ruiz nos obligamos de entrar a la parte / de las abarias y liman y pitiliman y mas / abarias acostunbradas e nos los dichos Juan / nyeto e bastian de amarante nos obligamos / de con los dichos tresçientos y çinquenta ducados / forneçeremos y probeeremos la dicha nao de / todo bastimyento e cossas nesçesarias que con / bengan y menester sean para hazer la dicha biaje / a la dicha tierranueba e pesca suso dicha sin / que falte de todo ello cossa nynguna dello $\left(\mathrm{XIIv}^{\circ}\right)$ e tienpo y haziendo y no perdiendo luego que la / dicha nao estubiere adreçada y apriezada para / ello que haremos y probreremos con toda deligencia / y cuidado que ser pueda seguiremos derecho biaje / a la dicha pesca e tierranueba para en todo / el mes de março primero que biene del año de myll / e qynientos e ochenta años y por razon de los dichos / tresçientos e çinquenta ducados y lo mas a / quy dicho y espaçificado en esta scritura que ansi / nos days para forniçimyento de la dicha nao e / bastimyentos della que hemos de cargar y llebar / nos los dichos maestros señorios y marineros he / mos de dar y entregar a bos los dichos diego de / hontiveros y francisco rruiz o a quyen vuestro poder / obiere luego que llegaremos a esta dicha villa / de pontebedra de la dicha pesca e tierra nueba / en ssalbamyento siendo dios serbido la terçia / parte enteramente de toda la pesca de bacalao / y de otro pescado de qualquyera genero que sea / que truxieremos en la dicha nao y obieremos to / mado en la dicha tierranueba como de toda la / graça que dello ssaliere y se hiziere con que / primero y ante todas cossas bos demos / y daremos demas de la dicha terçia parte de que bos / emos de dar tres myllares de bacalao de / bentaje otrosi bos daremos y entregaremos / la terçia parte de todas las baras maderas / y otras cossas que dende la dicha tierranueba $\left(\mathrm{XIIIr}{ }^{\circ}\right)$ a esta dicha villa traxieremos y ansy mysmo hes / condiçion entre nos las dichas partes que despues / de ansi llegada la dicha nao a esta dicha villa / y ssacado la pesca que en ella binyere daremos / y entregaremos nos los dichos maestros a bos / los dichos diego de hontiveros e francisco rruiz for / nydores la sobra de todo el pan bino barcos e / liñas y anzuelos betas y todo lo mas for / nymiento que ansi sobrare de lo que ansi nos days / para fornyçimiento de la dicha nao e yr a la dicha tierra / nueba e pesca susso dicha otrosi es condiçion / que abiendo de yr la dicha nuesta nao otra se / mejante biaje a la dicha tierranueba para / el año benydero de myll e quynientos y ochenta e un / años que queriendola fornir y bastezer / bos los dichos diego de hontiberos e francisco / Ruiz no bos la podamos quytar por darla / a otros y que primero sereis preferidos / que otros nyngunos e por ello bos lo haremos / ssaver y demas de todo lo que dicho hes / y se contiene en esta scritura si en la dicha / tierranueba obieremos o traxieremos otras / qualesquyer cossas ansi de pesca como de otra / manera que sea bos daremos y entregaremos / a bos los dichos francisco rruiz de liebana e diego / de hontiberos la terçia parte dello como de lo mas / llanamente sin faltar cossa nynguna de todo ello $\left(\mathrm{XIIIv}^{\circ}\right)$ y todas partes cada uno de nos por lo que le toca / de guardar y cumplir en esta scritura ansi lo guardaremos / y conpliremos so pena de los yntereses daños y menos / cabos que se siguieren y rrescre-çieren conforme a la ga / nançia que trajeren las naos y nabios de semejante / porte que ban dende abeiro a la dicha tierranueba / y costas y gastos que sobre ello se hizieren que den y pa / guen las partes que no lo cunplieren a los que lo que lo / cunplieren e por la seguridad y ssaneamyento dello ypotecamos los / unos a los otros y los otros a los otros la dicha / nao y aparejos y belas della y mercadoria y fornymyento / de bastimyen-to e por ello obligamos nuestras personas y bienes / muebles e rraizes avidos y por aver y damos todo / nuestro poder cunplido a todas las justiçias seglares / de su magestad a cuya juridiçion nos ssometemos y rre / nunçiamos a nuestro propio fuero juridi-çion y domiçilio / y a la ley sid conbenerid de juridiçiones o ninguna judi / cion para que por todo rremedio y rrigor del derecho e [)?] / [)?] executiva nos conpelan y apremyen / a lo cunplir y guardar bien ansi y a tan cunplida / mente como si esta carta y lo en ella contenido fuese 
/ sentencya defynytiva de juez conpetente por nos consentida / y pasada en cossa juzgada sobre lo qual renunciamos las / leyes e derechos en nuestro favor y a la ley y derecho que dize que general / renunçiacion de leys fecha que no balga e consentimiento de lo qual / otorgamos esta carta en la manera dicha antel escrivano publico e testigos yuso contenidos $\left(\mathrm{XIIII}{ }^{\circ}\right)$ que fue fecha y otorgada en la villa de ponte / bedra a siete dias del mes de dezienbre de myll e / quinyentos e setenta y nuebe años testigos que fueron / presentes a lo que dicho hes alvaro do paço e juan baz / quez vezinos de la villa de rribadavia e bartolome / diaz mareante vezinos y estantes en la dicha / villa e firmaronlo de sus nonbres los dichos / Diego de honteveros e francisco rruiz de liebana / y bastian de amarante e por el dicho Juan nyeto que dixo que no ssavia scrivir lo firmo un testigo / a su rruego a los quales otorgantes yo el / presente notario doi ffee que conozco.

\title{
ARQUIVO HISTÓRICO PROVINCIAL DE PONTEVEDRA (A.H.P.Po.)
}

\author{
Sección Ayuntamiento de Pontevedra Legajo 128 (10)
}

(f. LXXI ro) Contrabto delos qan deyr a las canaryas

En o nome de deus Amen ano del nascimiento de nuestro senor / Ihesu Xpo de myll e quinientos e veynte tres anos veinte e seis dias del mes / de setienbre sepan quantos deste contrabto de avinça e ygoala e conçierto vieren / como nos las partes aquy a juso contenydas conviene a saver Rodrigo / de cordeyro e Juan de camanço e Juan Gonsales e esteban Rodrigues o moço / e juan davilles o moço e pedro tilleyro o moço /

[espacio en blanco]/

que somos presentes mareantes vecinos de la moureyra arrabal de / la vylla de pontevedra que somos presentes fazemos e / otorgamos el presente contrabto de conçierto e ygoala / en la manera que dicha es que nos e cada uno de nos por sy nos / obligamos con nuestras personas e bienes mobles e rayzes / avydos e por aver e sub la pena a juso qontenida de plazendo a dios / yremos en una pinaça bordada a la gran canaria / a pescar toda la pescaria que dios nos diere plazendo / a dios por el primero dia del mes de enero del año / venydero de myll e quinientos e veynte e quatro años el qual pes / cado que ansy pescaremos e dios nos diere avemos / de llebar e partir cada uno la su justa parte que le copiere / e llebar cada uno su parte e ansy mysmo queremos e nos / obligamos que como partieremos plaziendo a dios desta / dicha vylla a pescar la dicha pescaria e se allare doliente / qualquyera de nos faltalle seremos plazendo a dios / desta dicha villa que nosotros todos le avemos de / fazer quiñon e dar parte dela dicha pescarya al / tal doliente e dolientes que se allaren mal e la su / parte que le cave como a cada uno de nos los dichos / conpañeros syn pleito e syn contenda ni rebol / de juyçio alguno e de la pescaria que Dios nos / diere avemos de dar e pagar un çento de pey / xes para la obra de Santa Maria la grande desta dicha / villa o su justo valor quella nos queyra ajudar / e nosa abogada e rogadora nos queyra ayudar (f. LXXI vo) e que nos los dichos juan de camanço e Ruy de cordeyro / e Juan Gonsales nos obligamos de catar el barco para / enel yr a la dicha pescaria e nos los sobredichos / les damos poder conplido e nos obligamos de / pagar cada uno la su justa parte que le copiere / e queremos e otorgamos e nos obligamos delo todo / ansy tener conplir e guardar segun e dela manera / que dicha es sopena de diez myll mrs pares de blancas / que otorgamos e nos obligamos de dar e pagar a / las partes de nos obedientes la mytad para la / justiçia que le exsaminare e la otra mitad para la / parte obediente e çerca dello renunçiamos todas / las leys foros e dereytos escritos e non escritos que en / contrario desto sean digan o aleguen pero que lo digan / que no valla la qual pena pagada o no pagada / toda ni a esta dicha carta e todas las costas / qontenidas y queden firmes e vallan para sienpre questan / visto çerca delo qual damos poder conplido 
a todas / las justiçias seglares delante quien esta carta paser / e della por pedido conplimyendo de justiçia que nos / fagan ansy tener conplir e guardar esta carta / elo en ella qontenido e pagar la pena en ella contenida / faziendo exsecuçion por la dicha pena en nuestras / personas e bienes vien ansy e tan conplida / mente como sy esta carta elo en ella qontenido fuese sentencia / definytiba dada por juez conpetente e la tal / sentencia contra nos fuese e oviese pasada en cosa juz / gada ansi de firmeza dello e otorgamos / ende el presente contrabto de conçierto en la / manera que dicha es ante notario publico e testigos de yuso / escritos e porque no savemos firmar rogamos a / Grigorio Duran Domingo e a Rodrigo Alonso que firmen por nos / de sus nombres neste registro deste dicho con (f. LXXII $\mathrm{r}^{0}$ ) trabto que fue fecho e otorgado en esta dicha villa de / Pontevedra año dia e mes sobredichos testigos / questaban presentes los dichos grigorio duran e / Rodrigo Alonso que firmaron de sus nonbres neste / registro de my notario e vastian fernandez trava / llador vecinos dela dicha villa de pontevedra / e yo el dicho notario doy fee que conosco a los dichos / otorgantes e son ellos mismos que / otorgaron este dicho contrabto e firmaron con sus / nonbres 